Section Editor

John J. Millichap, MD

Miya E. Bernson-Leung, MD

Gabrielle A. deVeber, $\mathrm{MD}, \mathrm{MHSc}$

Correspondence to

Dr. Bernson-Leung:

miya.bernson-leung@childrens. harvard.edu

\title{
Emerging Subspecialties in Neurology: Pediatric stroke and cerebrovascular disorders
}

In 1895, a neuropathologist at the University of Vienna observed that "a large number of cases of infantile cerebral palsy is caused by the same factors that bring about the majority of cases of cerebral paralysis of adults: by tearing, embolism, and thrombosis of cerebral vessels." While Sigmund Freud would go on to become better known for other endeavors, his observation that children can have strokes paved the way for the development of the emerging subspecialty of pediatric stroke and cerebrovascular disorders.

PEDIATRIC STROKE: CLINICAL ASPECTS Stroke, ischemic and hemorrhagic, is estimated to occur in at least $2-3$ per 100,000 children annually, and 1 in 4,000 neonates. ${ }^{2}$ This makes pediatric strokes relatively common among serious pediatric neurologic conditions. However, recognition by both parents and providers is often delayed due in part to lack of awareness of stroke as a disorder affecting children. ${ }^{3}$ While children show remarkable resiliency and potential for recovery, $20 \%-40 \%$ of children die after their stroke, and up to $80 \%$ experience poststroke disability compounded over decades of remaining life expectancy. ${ }^{2}$

Causes of stroke in children range from infectious and inflammatory arteriopathies to cardiogenic embolism to genetic and acquired thrombophilias and vascular abnormalities. Sites of pediatric stroke care delivery range from the emergency room and intensive care unit to rehabilitation centers and outpatient multidisciplinary clinics. The field is therefore inherently multidisciplinary, offering neurologists the opportunity to work together with numerous specialists across fields and settings. This interdisciplinary richness and variety appeal to many who choose the subspecialty.

CAREERS IN PEDIATRIC STROKE Pediatric stroke neurology is now a career option, one that offers significant rewards. The excitement of being on the cutting edge of a new field of discovery provides opportunities for challenging and stimulating intellectual and research pursuits. Pediatric stroke specialists will follow neonates and children with stroke from the onset of acute stroke through diagnosis and recovery, affording both the excitement of acute management and the fulfillment of long-term relationships with patients and families. Some pediatric stroke specialists will attend on both the pediatric and adult stroke services in the hospital, including sharing in both call pools. Others will see pediatric stroke patients as a portion of their clinical efforts, devoting other inpatient or outpatient time to critical care neurology or other general pediatric neurology. Many pediatric stroke neurologists also devote time to basic, translational, or clinical research. The parallel emergence of neuropsychologists, nurse practitioners, and rehabilitation therapists focused on pediatric stroke provides opportunities for a team approach in both clinical care and research. Finally, children with stroke and their parents have formed strong collaborations with health practitioners in this field, providing partnership in advocacy for children with stroke (see Resources).

HISTORY OF THE FIELD Until the 1990s, there was little forward movement in pediatric stroke. Then, neurologists and hematologists convened the first pediatric stroke interest groups and symposia at the Institute of Child Health, London, United Kingdom. The field was defined as interdisciplinary and collaborative from the outset. To overcome the challenge of studying a relatively uncommon condition, hematologist Maureen Andrew and neurologist Gabrielle deVeber founded the Canadian Pediatric Ischemic Stroke Registry in 1992 and the "1-800-NOCLOTS" telephone consultation database in 1994, gathering data on thousands of cases. This ultimately led to the 2003 creation of the International Pediatric Stroke Study (IPSS), a database currently approaching 5,000 cases of pediatric stroke from 215 centers in 54 countries around the world (figure). The IPSS has produced 22 publications, and multiple NIH-funded studies. The Pediatric Stroke Outcome Measure, developed in 1995, enables cross-center comparisons of outcomes similar to adult measures such as the modified Rankin Scale. ${ }^{4}$ A pediatric version of the National Institutes of Health Stroke Scale (NIHSS), the

From the Department of Neurology (M.E.B.-L.), Boston Children's Hospital, MA; and the Department of Neurology (G.A.d.), Hospital for Sick Children, Toronto, Canada.

Go to Neurology.org for full disclosures. Funding information and disclosures deemed relevant by the authors, if any, are provided at the end of the article. 


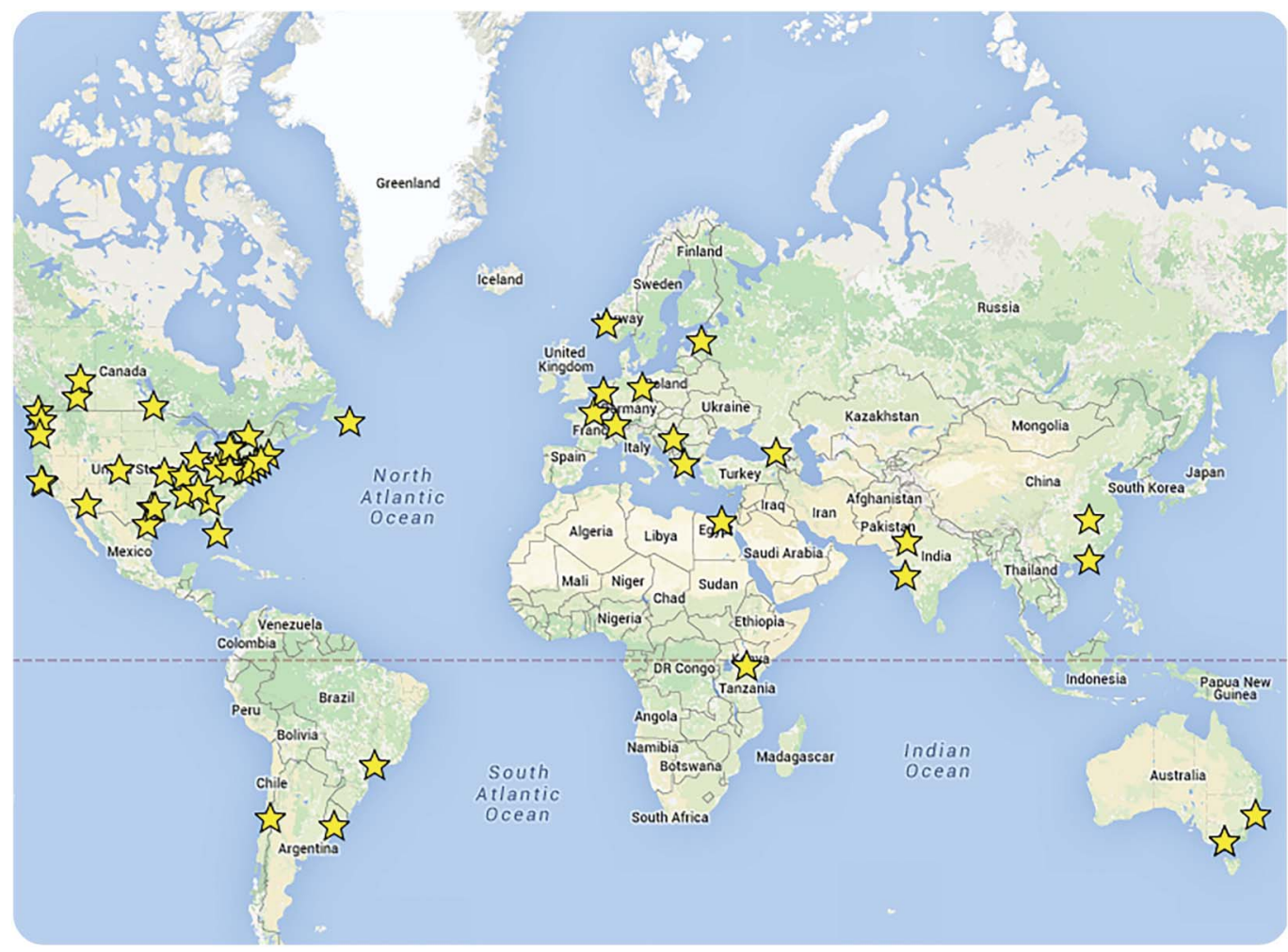

The community of pediatric stroke neurologists is truly international. The International Pediatric Stroke Study group currently consists of 150 active investigators at 55 sites worldwide. As of February 2016, 4,967 patients were enrolled from a total of 215 centers.

PedNIHSS, was validated in 2011.5 Three sets of guidelines have been published by the Royal College of Physicians, the American Heart Association/ American Stroke Association, and the American College of Chest Physicians to summarize existing evidence and provide recommendations for diagnosis and management of pediatric stroke. ${ }^{2,6,7}$ Clinical and translational research related to pediatric stroke is booming; in the last 15 years, there have been over 1,500 publications. Finally, centers of excellence are developing analogous to adult primary and comprehensive stroke centers, with at least 17 centers now prepared to diagnose and treat pediatric stroke based upon standardized protocols. ${ }^{8}$ Acute and longterm treatment trials in pediatric stroke are underway.

FELLOWSHIP TRAINING Pediatric stroke has emerged not only as a field of practice but also as a dedicated training pathway. Before dedicated training programs existed, current leaders in the field trained in adult neurology, pediatric neurology, or hematology. A pediatric stroke fellowship was established in 1998 at Toronto Children's Hospital, and other programs have followed, responding to the need for future pediatric stroke neurologists to master an understanding of pediatric stroke and individualized application of emerging guidelines and standards of care in addition to knowledge of the rapidly expanding literature. Dedicated training offers fellows not only depth of experience based on caring for a sufficient volume of pediatric stroke cases, but also breadth, seeing many unique disorders associated with pediatric stroke that are unlikely to be encountered in regular residency training. Fellows gain experience in providing acute stroke care within complex systems, leading "stroke codes" under the supervision of attending stroke specialists. As fellowship training generally includes both adult and pediatric clinical experience, stroke fellows also gain experience with stroke syndromes in adults and with models of stroke care delivery in established adult stroke centers. Depending on the training program, some pediatric stroke fellows are eligible for Vascular Neurology board certification by the American Board of Psychiatry and Neurology. Finally, fellowships offer the opportunity for mentored research experience to launch a career in academic medicine.

Multiple training pathways are open to trainees interested in pediatric stroke. At present, 5 academic centers in North America offer clinical and research fellowships in pediatric stroke and cerebrovascular disorders on an ongoing basis: The Hospital for Sick 
Children in Toronto, Children's Hospital of Philadelphia, Boston Children's Hospital, the University of Calgary, and the University of Colorado. Additional centers including the University of California San Francisco, Johns Hopkins University, and the University of Texas-Houston have accepted child neurology trained applicants to their vascular neurology fellowships accredited by the American College of Graduate Medical Education (ACGME); only ACGME-accredited programs confer eligibility for board certification. Other trainees may choose to pursue established fellowships in adult or pediatric critical care or neurocritical care, a related emerging subspecialty with an emphasis on acute management of neurologic emergencies. ${ }^{9}$ Other centers with pediatric stroke expertise may be willing to customize a program for interested trainees.

While the length and composition of pediatric stroke training programs vary, all typically include a combination of inpatient and outpatient clinical experience in pediatric stroke and related disorders. Most have some clinical time devoted to adult stroke. Additional clinical exposures that programs may provide include neurosurgery, interventional neuroradiology, hematology, rehabilitation, and critical care. Some programs include formal training in research methodology. To further trainee education, programs typically include teaching conferences and journal clubs, including with the adult stroke fellows from sister programs. Pediatric stroke trainees may also become involved with clinical education for other neurologists through consultations or formal teaching opportunities, as well as with interprofessional education. Pediatric stroke trainees benefit from exposure to the state of the field and the larger pediatric stroke community through attendance and presentations at conferences. As the number of pediatric stroke trainees grows, collaboration across training programs would provide further opportunities to enhance training. Perhaps in the future there may even be a board certification in pediatric vascular neurology.

EXPLORING THE FIELD Neurology trainees and medical students interested in learning more about the field of pediatric stroke should feel welcomed and encouraged to explore this career path and consider dedicated training. Clinical rotations at institutions with pediatric stroke specialists and a high volume of pediatric stroke patients offer an excellent introduction to the field. Research projects in topics related to pediatric stroke are an opportunity to become familiar with and contribute to the burgeoning literature. Finally, attendance at sessions related to pediatric stroke at annual conferences including the International Stroke Conference, Child Neurology Society, and American
Academy of Neurology offer an up-to-date overview of the field and its exciting new developments. The IPSS holds investigator meetings in conjunction with the International Stroke Conference and Child Neurology Society annual meetings.

FUTURE DIRECTIONS The future of the field of pediatric stroke is bright, with increasing workforce demand for pediatric stroke clinicians and many opportunities for further research. Clinical trials in stroke treatment are urgently needed and increasingly feasible given the increasing capacity of pediatric centers to deliver acute stroke care. Such treatments will require increased crossdisciplinary collaboration. In parallel, new technologies are being explored to bring subspecialty expertise including acute stroke care into the community: telestroke systems for adult patients have enabled rapid, remote assessment and treatment, and this is an important area of future development for children with symptoms of stroke. ${ }^{10}$ Finally, understanding the mechanisms of pediatric stroke is increasingly possible through advanced neuroimaging, genetic testing, and other areas of scientific progress. Trainees who are excited by the prospect of a multidisciplinary, collaborative, and rapidly evolving field of clinical care and research will find pediatric stroke and cerebrovascular disorders to be a rewarding subspecialty.

\section{ADDITIONAL ONLINE RESOURCES}

- International Pediatric Stroke Study: app3.ccb. sickkids.ca/cstrokestudy/

- American Heart Association/American Stroke Association Stroke in Children: strokeassociation.org/STROKEORG/About Stroke/StrokeInChildren/Stroke-In-Children UCM_308543_SubHomePage.jsp

- Pediatric National Institutes of Health Stroke Scale (PedNIHSS) (data supplement to Ichord et al. ${ }^{5}$ ): stroke.ahajournals.org/content/suppl/ 2011/02/17/STROKEAHA.110.607192.DC1/ 607192_ONLINE_SUPPLEMENT.pdf

\section{ADVOCACY AND SUPPORT ORGANIZATIONS (SELECTED)}

- International Alliance for Pediatric Stroke: iapediatricstroke.org

Also see local organizations: iapediatricstroke. org/organizations.aspx

- World Pediatric Stroke Organization: http:// www.worldpediatricstrokeassociation.org/

- Canadian Paediatric Stroke Support Association: cpssa.org

- Children's Hemiplegia and Stroke Association: chasa.org

- StroKidz: strokidz.com 


\section{AUTHOR CONTRIBUTIONS}

Dr. Bernson-Leung drafted the manuscript. Dr. deVeber critically revised the manuscript for intellectual content. Both approve the manuscript in its final form.

\section{STUDY FUNDING}

No targeted funding reported.

\section{DISCLOSURE}

M.E. Bernson-Leung is a former member of the Resident \& Fellow Section and a fellow in the Stroke and Cerebrovascular Disorders program at Boston Children's Hospital. G.A. deVeber is the director of the Canadian Pediatric Ischemic Stroke Registry and the International Pediatric Stroke Study and creator of the Pediatric Stroke Outcome Measure. Go to Neurology.org for full disclosures.

\section{REFERENCES}

1. Rothman SM. Stroke in children: Freud's first analysis. Lancet 2002;360:1526-1527.

2. Roach ES, Golomb MR, Adams R, et al. Management of stroke in infants and children: a scientific statement from a Special Writing Group of the American Heart Association Stroke Council and the Council on Cardiovascular Disease in the Young. Stroke 2008;39:2644-2691.

3. Mallick AA, Ganesan V, Kirkham FJ, et al. Diagnostic delays in paediatric stroke. J Neurol Neurosurg Psychiatry 2015;86:917-921.
4. deVeber GA, MacGregor D, Curtis R, Mayank S. Neurologic outcome in survivors of childhood arterial ischemic stroke and sinovenous thrombosis. J Child Neurol 2000; 15:316-324.

5. Ichord RN, Bastian R, Abraham L, et al. Interrater reliability of the Pediatric National Institutes of Health Stroke Scale (PedNIHSS) in a multicenter study. Stroke 2011;42: 613-617.

6. Paediatric Stroke Working Group. Stroke in Childhood: Clinical Guidelines for Diagnosis, Management and Rehabilitation. London: Royal College of Physicians; 2004.

7. Monagle P, Chan AK, Goldenberg NA, et al. Antithrombotic therapy in neonates and children: Antithrombotic Therapy and Prevention of Thrombosis, 9th ed: American College of Chest Physicians Evidence-Based Clinical Practice Guidelines. Chest 2012;141(2 suppl):e737S-e801S.

8. Bernard TJ, Rivkin MJ, Scholz K, et al. Emergence of the primary pediatric stroke center: impact of the thrombolysis in pediatric stroke trial. Stroke 2014;45:20182023.

9. LaRovere KL, Riviello JJ Jr. Emerging subspecialties in neurology: building a career and a field: pediatric neurocritical care. Neurology 2008;70:e89-e91.

10. Kuhle S, Mitchell L, Andrew M, et al. Urgent clinical challenges in children with ischemic stroke: analysis of 1065 patients from the 1-800-NOCLOTS pediatric stroke telephone consultation service. Stroke 2006;37:116-122. 


\section{Neurology}

\section{Emerging Subspecialties in Neurology: Pediatric stroke and cerebrovascular disorders}

Miya E. Bernson-Leung and Gabrielle A. deVeber

Neurology 2016;87;e219-e222

DOI 10.1212/WNL.0000000000003291

\section{This information is current as of October 31, 2016}

\section{Updated Information \&} Services

References

Subspecialty Collections

\section{Permissions \& Licensing}

Reprints including high resolution figures, can be found at: http://n.neurology.org/content/87/18/e219.full

This article cites 9 articles, 6 of which you can access for free at: http://n.neurology.org/content/87/18/e219.full\#ref-list-1

This article, along with others on similar topics, appears in the following collection(s):

All Cerebrovascular disease/Stroke

http://n.neurology.org/cgi/collection/all_cerebrovascular_disease_strok e

All Education

http://n.neurology.org/cgi/collection/all_education

Childhood stroke

http://n.neurology.org/cgi/collection/childhood_stroke

Pediatric stroke; see Cerebrovascular Disease/ Childhood stroke http://n.neurology.org/cgi/collection/pediatric_stroke_see_cerebrovasc ular_disease-childhood_stroke

Information about reproducing this article in parts (figures,tables) or in its entirety can be found online at:

http://www.neurology.org/about/about_the_journal\#permissions

Information about ordering reprints can be found online: http://n.neurology.org/subscribers/advertise

Neurology ${ }^{\circledR}$ is the official journal of the American Academy of Neurology. Published continuously since 1951, it is now a weekly with 48 issues per year. Copyright () 2016 American Academy of Neurology. All rights reserved. Print ISSN: 0028-3878. Online ISSN: 1526-632X.

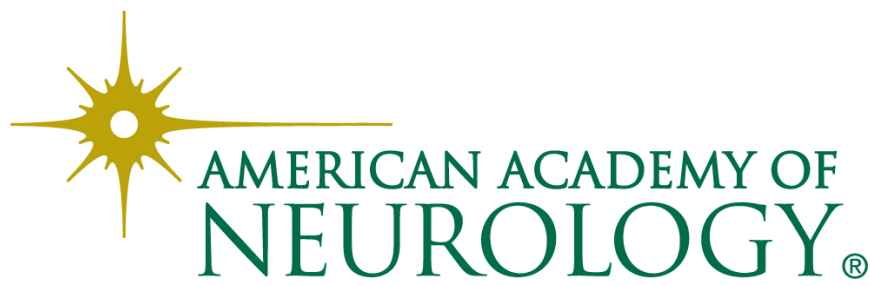

